\title{
SYNTHESIS
}

Synthesis, vol. 25, $\mathrm{n}^{\circ}$ 2, e039, diciembre 2018. ISSN 1851-779X

Universidad Nacional de La Plata.

Facultad de Humanidades y Ciencias de la Educación.

Centro de Estudios Helénicos

\section{Héctor, un "héroe" controvertido en Reso de Pseudo-Eurípides}

Hector, a controversial "hero" in Pseudo-Euripides' Rhesus

Maria de Fátima Silva*

Universidad de Coimbra, Portugal

fanp@ci.uc.pt

\section{RESUMEN:}

La autoría del Reso sigue siendo motivo de controversias; sin embargo, las marcas épicas y trágicas son decisivas en su estructura y estilo. Nuestra reflexión va a centrarse en Héctor, a quien varios comentadores consideran, con razón, su protagonista. Existe consenso al reconocer que su versión trágica pierde en prestigio y humanidad, comparada con su modelo épico. En primer lugar, hay un rasgo omitido en la tragedia, en buena parte responsable por esta desvalorización: el que ahora reina sobre Troya prescinde de la faceta de defensor de los suyos, de héroe preocupado por su pueblo, o incluso sensible en sus relaciones personales con su madre Hécuba, su esposa Andrómaca y su hijo Astianacte, y también con la causante de la crisis en la ciudad, Helena. Está, por lo tanto, circunscrito a la condición de guerrero y sobre todo a los criterios que, en esta medida, deben guiar su comportamiento: la autoridad sobre los subordinados y el tratamiento dado al enemigo. Es puesto a prueba en lo que son las normas de un código de honor, donde el aidós, la sophrosýne y la philía garantizan, en un ejército de troyanos y sus aliados, cohesión y éxito.

Palabras Clave: Iliada, Doloneia, Euripides, Agônes.

\section{Abstract:}

The authorship of Rhesus is a controversial subject, although the epic and tragic marks are clear in its structure and style. In this study we will focus on Hector, the protagonist to several commentators. There seems to be a consensus that his tragic version loose prestige and humanity if compared with his epic model. First of all, tragedy omits a trace mainly responsible for this devaluation: the king now in charge of Troy is not the defensor of his people, or the man sensitive in his personal relationships with his mother, Hecuba, his wife and son, Andromache and Astianax, or even with the cause of all evils, Helen. Hector is now only the warrior who acts under the values related to this condition: authority in front of his subordinates and treatment of the enemy. He is confronted with a code of honor, where aidos, sophrosyne and philia assure to the army, of Trojans and their allies, cohesion and success.

KEYWORDS: Iliad, Doloneia, Euripides, Agones.

Seguimos con la discusión, seguramente insoluble, ${ }^{1}$ sobre la autoría euripídea del Reso, discusión que comporta además la cuestión de la fecha y del marco de la obra dentro de un cierto modelo de tragedia más o menos antiguo. Por lo tanto, la valoración de aspectos relevantes de tema y estructura ha sido un criterio que parece conducir a la conclusión de que, si hay mucho de Eurípides en esta obra, no es menos verdad que se perciben igualmente marcas de otros autores; $y$ en contrapartida hay opciones formales, en el tratamiento del coro por ejemplo, que constituyen infracciones a lo que fueron las reglas siempre observadas, de forma variable es cierto, por los autores de las obras que conservamos en su totalidad, Esquilo, Sófocles y Eurípides, ${ }^{2}$ apuntando tal vez a una época más tardía (finales del siglo V o eventualmente el siglo IV a. C.), cuando los nombres de referencia habían ya desaparecido o cumplían la parte final de su trayectoria artística. ${ }^{3}$ Parece así que tal vez la conclusión más acertada sea defender una autoría distinta para el Reso, sin dejar de reconocer las influencias directas -empezando con el lenguaje- que este otro poeta asimiló de sus exitosos predecesores, con probable predominio de Eurípides.

Además de las marcas trágicas, tema y lenguaje apuntan a otro modelo de influencia decisiva, la Ilíada, en particular su canto X, la Dolonia. ${ }^{4}$ En líneas generales, la intriga del Reso retoma el momento en que el ataque troyano contra la empalizada enemiga -tras la retirada de Aquiles- garantiza al ejército de Héctor alguna ventaja y, en consecuencia, la reacción de los aqueos se hace imprevisible (Il. VIII). Es para conocer 
qué intenciones los mueven -de retirada o de una reacción traicionera- que una misión de espionaje se manifiesta esencial y Dolón se ofrece como voluntario para llevarla a cabo. A la vez, del lado adversario, Diomedes y Odiseo asumen una misión paralela en terreno troyano. Definida una trama común entre la epopeya y el Reso, hay que reconocer desde luego las alteraciones y nuevas proporciones del mito que se verifican en la versión trágica, dentro de una práctica muy convencional del tratamiento del mito y de la recepción de las versiones inmortalizadas por los viejos poetas del pasado. Es, pues, dentro de este criterio innovador que nos proponemos analizar esa figura que es central en la acción del Reso, ${ }^{5}$ Héctor, en este caso "el rey de Troya" (Reso 2), para fundamentar su nuevo perfil, partiendo de sus decisiones y actitudes, dentro del entramado de relaciones que establece con compañeros, aliados, subordinados y enemigos.

Se suele reconocer que el Héctor trágico pierde en prestigio y humanidad comparado con su modelo épico. ${ }^{6}$ En primer lugar, hay un rasgo omitido en la tragedia, en buena parte responsable por esta desvalorización: el que ahora reina sobre Troya prescinde de la faceta de defensor de los suyos, de héroe preocupado por su pueblo, o incluso sensible en sus relaciones personales con su madre Hécuba, su esposa Andrómaca y su hijo Astianacte, y también con la causante de la crisis en la ciudad, Helena. Está, por lo tanto, circunscrito a la condición de guerrero y sobre todo a los criterios que, en esta medida, deben guiar su comportamiento: la autoridad sobre los subordinados y el tratamiento dado al enemigo. Es puesto a prueba en lo que son las normas de un código de honor, el aidós ("vergüenza") que evita la cobardía y anima a la determinación, la sophrosýne ("sensatez") en las decisiones y la philía ("solidaridad”) que garantiza, en un ejército de troyanos y sus aliados, cohesión y éxito.

\section{EL JEFE ANTE SUS SUBORDINADOS, IGUALES O ALIADOS}

Es pues como guerrero que Héctor ocupa un lugar de gran protagonismo en la obra. Pero los sucesivos enfrentamientos con distintos interlocutores, que la tragedia organiza en una alternancia creciente, tienden a dejar al descubierto, bajo el lado visible del jefe de los troyanos, emociones o sentimientos que lo dibujan también como hombre. El resultado es el prototipo de un héroe de modelo épico, cubierto ahora por los tonos más humanizados y trágicos del ser humano investido de responsabilidad en la conducción de los destinos de un pueblo. Y aunque el código de valores que el poeta de la Ilíada ha manifestado en el campo de batalla -areté, sophrosýne, timé, aidós- siga en debate en el Reso, la decadencia es manifiesta, sobre todo si se evalúa a partir del comportamiento y las actitudes del jefe troyano. De defensor indómito de su patria y de los suyos, lo vemos desplazado a la condición de un jefe precipitado, y, por ello, débil en el comando, individualista en sus objetivos, constantemente confrontado con oposiciones de iguales y subordinados que detentan una mayor lucidez en las decisiones, que le exigen revocar frecuentemente sus resoluciones y lo obligan a producir fisuras en el ejercicio de la autoridad. Asimismo, si alguna rehabilitación final parece poner moderación al tono general que es de censura, no alcanza para recuperar, en toda su plenitud, la excelencia épica del único enemigo a la altura del gran campeón de los aqueos, Aquiles.

Una cuestión de contexto general de la obra -que toda la acción transcurra durante la noche- determina una primera condición para el desmontaje de la figura homérica. Héctor cedió al sueño (Reso 1-10, 87-9, 643-5), ${ }^{7}$ seguramente vencido por el esfuerzo que la arremetida del día anterior le había exigido, pero tal vez también imprudentemente liberado de mayores preocupaciones porque estaba convencido del ascendiente que la victoria alcanzada en la víspera le podría garantizar. Esta, su pasividad, que es igualmente ausencia, degenera en debilidad, cuando es confrontada con la agitación que reina en el campo adversario, donde los jefes, despiertos, responden a dudas de sus subordinados y diseñan la necesaria reacción $(41-8) .{ }^{8}$ La sorpresa o incluso censura que este dormirse merece, en varios tonos, del coro de centinelas primero y después de Eneas y Paris Alejandro, es síntoma manifiesto de una fragilidad del jefe que todos buscan, absorbidos por una preocupación a la que tan solo él parece ajeno. Por lo tanto, dentro y fuera del campamento troyano, el sueño de Héctor parece excepcional y, aunque justificado, no lo ennoblece. 
A la abulia, que el sueño justifica, le sigue, sin una transición racionalizada, la precipitación. La simple recomendación del coro, a un Héctor que aparece desde el interior de la tienda mal despierto, de que "tenga calma" (15) es suficiente para permitir el registro de que el jefe impresiona a los subordinados por la emoción patente como resultado de la sorpresa, pero también como un rasgo natural en su personalidad -como se confirmará muchas veces en su comportamiento futuro-. Esta es una característica que se vuelve debilidad y posibilita que los propios centinelas, más alertados de la real dimensión del problema, le sugieran qué órdenes dar (23-33), ${ }^{9}$ un hecho que constituye una originalidad flagrante en la misión que se espera de un coro.

En cierto sentido, las noticias que le son transmitidas por los centinelas que forman el coro, de que el enemigo mantiene el campamento iluminado y que el insomnio entre los aqueos es general, son alarmantes, y ante ellas, Héctor apuesta por una única lectura: la de que el enemigo se prepara para una fuga improvisada. ${ }^{10}$ Un tremendo sentimiento de "vergüenza" ante la posibilidad de estar siendo víctima de una trampa y de que el enemigo, en desventaja, se escape a una derrota retumbante, le perturba la razón; lo domina algo que se acerca a una cierta arrogancia o defensa egoísta de su propia imagen y prestigio; da por seguro el éxito anterior y descuida la salvaguarda del futuro $(83) ;{ }^{11}$ por ello, sin más ponderaciones, avanza con una orden de ataque en plena oscuridad (70-1).

Respondiendo a la urgencia de las instrucciones dadas, en las que "la prisa" ( $\dot{\varsigma} \varsigma \dot{\alpha} \chi\llcorner\sigma \tau \alpha, 70)$ domina, el coro instala en el diálogo la censura por la precipitación de Héctor ( $\tau \alpha \chi \dot{v} v \varepsilon ı \varsigma, 76)$, por el impulso que da a la

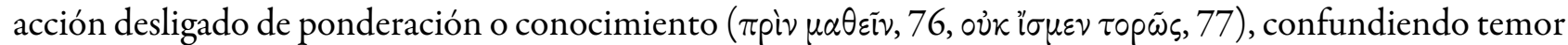
con prudencia (80); sensato sería por lo menos "desconfiar" (79) de las verdaderas intenciones del adversario, antes de asumir estrategias eventualmente inapropiadas.

Cuando este primer enfrentamiento con un subordinado deja como nota final la imprudencia del jefe, ya se anuncia, como un segundo interlocutor del soberano, la llegada de Eneas, con palabras particularmente significativas (85-6): "Pero allí viene Eneas y a toda prisa. Algo nuevo tiene que decirles a sus amigos". Si "la prisa” con que Eneas se acerca parece coincidir con la urgencia hasta aquí manifestada también por Héctor, un contraste profundo los separa: no se trata para el hijo de Anquises de salvar su propia reputación, enfocado en cualquier sentimiento de orgullo o de presunción; lo que lo mueve es el interés colectivo, una complicidad manifiesta con sus philoi. Tener como blanco prioritario a los enemigos o a los "amigos" es totalmente diferente, aconseja prudencia donde antes predominaba la precipitación. Eneas es, por lo tanto, el compañero o el igual del soberano, que viene a traerle una colaboración desinteresada y altruista en su papel de consejero.

Aunque entienda los temores de Héctor como justificados, Eneas quiere "pruebas" “¿Qué prueba segura

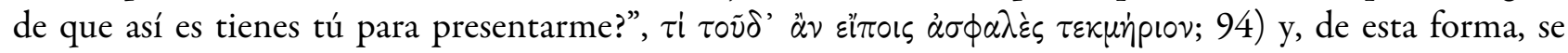
expone como poseedor de una racionalidad transparente. En respuesta, obtiene del soberano un tímido

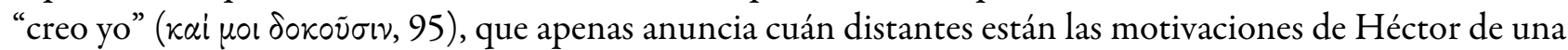
necesaria ponderación. En contrapartida, el temor a la "vergüenza", ya antes en él perceptible, se vuelve ahora manifiesto (100-4), ${ }^{12}$ de modo de instalar entre los dos troyanos un agón implícito. Encarnados por dos modelos paradigmáticos, los argumentos intercambiados suscitan un principio a valorar: que las diferentes virtudes no confluyen en un solo hombre, y este es el caso, tratándose del combate, de la sensatez ( $\dot{\jmath} \beta$ ßovi $\alpha$ ) y del vigor físico $(\delta \rho \tilde{\alpha} \sigma \alpha \iota \chi \chi \varepsilon p i, 105-7) ;{ }^{13}$ "cada uno con su talento: el tuyo es la lucha, el de otros el buen

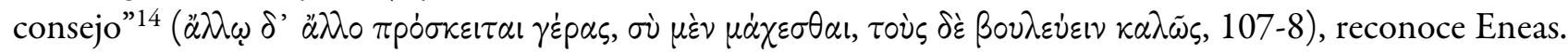
Ante las noticias que le trae el cuarto centinela, el rey -es evidente para su interlocutor- "se

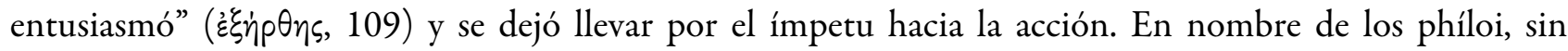
embargo, y de su seguridad, el consejero que Eneas representa alerta sobre los peligros; si hay riesgo de una trampa esa no debe ser medida solo como un propósito de fuga, que justifique una arremetida inmediata, sino como el objetivo de atraer a la ruina a un enemigo desprevenido. La oscuridad sería, para las fuerzas que 
se mueven en el terreno, un marco de imprevisibilidad, que no les dejaría valorar la verdadera intención del adversario: ¿será que, en vez de ponerse en fuga, los aqueos se estarían preparando para enfrentarse a un avance troyano? $\mathrm{Y}$ en ese caso, ¿cómo garantizar la retirada sin enormes daños para un ejército desordenado? Y si las condiciones de contexto no son favorables, el menosprecio con el que Héctor tiende a mirar al enemigo puede contribuir igualmente a un desenlace infeliz. El nombre de Aquiles -el adversario épico más temible que, en la obra, no pasa de una amenaza a distancia pero aun así considerable- entra naturalmente en el consejo de Eneas, como el símbolo de una areté que hay que tener en cuenta. La estrategia adecuada -que a través de una misión de espionaje puedan enterarse de las verdaderas intenciones del enemigo (125-30) - es propuesta por Eneas y secundada por el elogio del coro, como condición previa a una acción verdaderamente ponderada (147). ${ }^{15}$ Héctor termina humillado por censuras $(131),{ }^{16}$ forzado a reconocer su imprudencia y a tomar la iniciativa contraria a la que proponía. Está abierto el camino a un nuevo enfrentamiento, esta vez con Dolón, el espía.

Hijo de un padre de nombre discreto aunque de fortuna reconocida entre los troyanos, ${ }^{17}$ Dolón no es propiamente un guerrero distinguido; ${ }^{18}$ su posición en la jerarquía militar y su convivencia con la casa real son distintas de las que le caben a Eneas. En primer lugar, el llamamiento al que responde está dirigido a

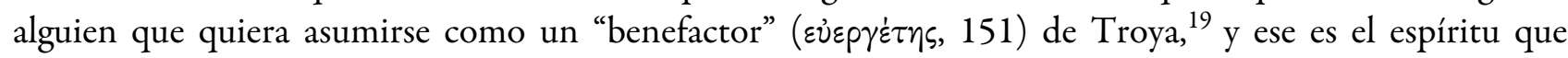
justifica la prontitud de su disponibilidad (154-7). ${ }^{20}$ Pero a pesar de estas disposiciones, no se trata de hecho, en la escena que ahora se inicia, de discutir como antes la areté de un verdadero héroe o patriota, sino de colocar por delante de cualquier otro objetivo, el premio, estimulante y merecido. Porque -en breve lo sabremos- la misión que acepta desempeñar no está exenta de alguna ambición y organizada estratégicamente con recurso al dolo, tan en conformidad con su propio nombre. ${ }^{21}$ Sin duda que se trata de colocar en riesgo su propia vida en beneficio, en primer lugar, de Troya. Pero el patriotismo y la generosidad son valorados en armonía con objetivos más terrenales, confesados en la discusión previa entre el espía voluntario y su rey. Las propias palabras con las que reivindica una compensación - no $\tau \iota \mu \dot{\eta}$, el

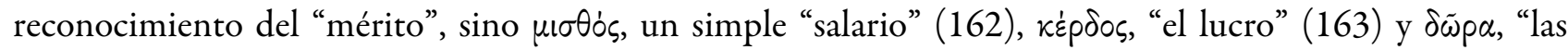
dádivas" debidas $(172,192)$ - sirven para denunciar el nivel básico de sus pretensiones. Héctor, por su parte, le responde con $\gamma^{\dot{\varepsilon} p a \varsigma, ~ " l a ~ g a r a n t i ́ a ~ d e ~ r e c o n o c i m i e n t o " ~}(169,181)$, considerando sin embargo que la propiedad de la pareja de caballos que ambiciona es, más que el reconocimiento de su valentía, una

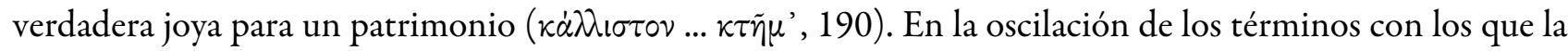
recompensa es mencionada parece haber además una diversidad de valores: Dolón sobre todo predispuesto por la valorización material del regalo concedido, Héctor no del todo insensible al sentido simbólico y honorífico que pueda tener dentro de la comunidad militar. Pero si consideramos la lista de prioridades que el rey de Troya adelanta como posibles pretensiones de su colaborador, no dejaremos de retirar de ellas alguna sugerencia para lo que es, desde el punto de vista del propio Héctor, la expresión deseable de la timé. ¿Qué distinciones consideraría él como compensadoras para un "benefactor" de la patria?

La medida que Héctor tiene de "premio" omite, por ejemplo, la que su modelo homérico había colocado como un objetivo primordial, la gloria, para fijarse en ventajas materiales y de estatus social más a medida de

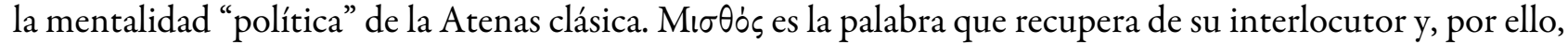
coloca a la cabeza de una lista de prioridades el poder, traducido en el propio trono de Troya (165), después una boda dentro de la familia real (167), o, también, simplemente oro (169). Estos podrían ser los premios conferidos en el marco de las posibilidades de la propia ciudad. ${ }^{22}$ Pero adelantando ya algún aspecto sobre el entendimiento que tiene del tratamiento del enemigo, Héctor establece, como última hipótesis, el deseo de venganza contra los jefes enemigos que Dolón pueda alimentar; y aunque recuse a priori esa barbaridad, ni aun así ella deja de sobrevenirle al espíritu (173-9). Superadas todas estas expresivas hesitaciones, el premio finalmente revelado es el que la tradición homérica había consagrado: los caballos de Aquiles. ${ }^{23}$ En él confluyen la ambición de ambos, soberano y voluntario para la misión de espionaje. Y ahí están los rivales, por lo menos presuntos, ${ }^{24}$ en un mismo objetivo, el de lograr un trofeo envidiable y, por detrás de él, el de 
afirmarse como dignos opositores y vencedores del mejor de los enemigos. Pero también en esta pretensión, Héctor cede, para dar prioridad al actual "benefactor" de la patria. ${ }^{25}$

Un pastor del Ida, en el papel de mensajero, anticipa la entrada triunfal de Reso, quien da nombre a la obra. El diálogo que entre ambos -soberano de Troya y siervo- se pone en marcha es una especie de prólogo a la llegada apoteósica de Reso, pero debe ser leído igualmente como una aportación más al diseño de Héctor, en el papel de soberano delante de sus subordinados y aliados. La precipitación sigue siendo el rasgo esencial en la personalidad del monarca de Troya; leyendo superficialmente las razones de la presencia del pastor y antes de enterarse del real sentido de su mensaje, ya Héctor se da prisa en censurarlo (264-74). Displicentemente contrasta preocupaciones guerreras con vulgares cuestiones pastoriles, despide al mensajero como inoportuno cuando intereses superiores del combate están en juego. Solo expone, de forma más visible, la imprudencia de su razonamiento. Al final el pastor es mensajero de noticias de guerra, de importancia primordial para el momento -la llegada de un aliado que puede alterar el desenlace de las hostilidades-. Y después de identificar al recién llegado como Reso, Héctor prosigue con nuevos errores de estrategia, al sorprenderse con el recorrido discreto que el tracio ha preferido, circulando por las alturas del Ida, en vez de exponerse en la planicie a cualquier asalto enemigo. Esta precaución, que no pasa desapercibida a cualquier mente banal, tiene que ser explicada al soberano de Troya por el más humilde de sus siervos, un simple cuidador de rebaños $(282-6){ }^{26}$

Una primera descripción del pastor devuelve, finalmente, la imagen imponente de ese a quien el título prometía como el protagonista de esta obra. Y antes que el público pueda apreciarla con sus propios ojos, son adelantados algunos aspectos fundamentales que prometen, para un inevitable agón con Héctor, un adversario de peso. En nombre del poeta, el pastor se refiere a esta nueva figura con una denominación identificativa (277): la de "amigo y aliado" de los troyanos ( $\phi i \lambda \circ \varsigma \sigma o l \sigma \dot{v} \mu \mu \alpha \chi \dot{s} \varsigma \varepsilon$ ). Y le adelanta como características: el susto que su presencia y el ruido por ella provocado han causado entre los habitantes de la montaña $(287,291,295)$; el porte casi divino que impresionaba en el conductor del ejército (301); ${ }^{27}$ el número abrumador de hombres bajo su mando (311-3). Este es, en la opinión del pastor, el adversario indicado para Aquiles (315-6), comentario que condena, de forma involuntaria pero no por ello menos expresiva, al adversario digno del hijo de Peleo que Héctor es en la Ilíada.

Pero ya el rey troyano, a su vez, se mide con el recién llegado, afirmando sus propios méritos en los éxitos ya alcanzados en el campo de batalla y depreciando la llegada tardía y casi inútil de quien se considera como amigo o aliado. ${ }^{28}$ Estaba definido, con este primer comentario de Héctor, el tema a desarrollar en la escena inminente: $\phi i \lambda i \alpha$ y $\sigma v \mu \mu \alpha \chi i \alpha$, otros dos conceptos relevantes en el código de valores sociales y militares, en discusión en esta tragedia.

La prudencia sugerida por el coro cuando se trata de aliados - un bien del que cualquier ciudad desea ser acreedora, ante la precariedad de las victorias y la imprevisibilidad del azar (330-2,334) - no inhibe a Héctor de proseguir en su ataque "a los falsos amigos”, en lo que es un ímpetu más de su incorregible precipitación. Sin saber aún cuáles son los motivos del retraso, ya se apresura a jerarquizar las condiciones de "aliado" y de "huésped" -"pero entonces, ya que ha llegado, pues que venga no como un aliado, sino como un huésped a la mesa de sus hospederos, ${ }^{29}$ porque ya perdió la simpatía de la casa de Príamo", 336-8- y a anticipar un conflicto diplomático. Luego se ve de nuevo compelido a retroceder y, ante las censuras explícitas del pastor y del coro, a devolver a Reso su condición de aliado. Es, por lo tanto, entre aliados, que se va a lidiar la contienda verbal siguiente. ${ }^{30}$

Y, como aliados y también semejantes en la convicción de sus éxitos, los ahora enfrentados esgrimen argumentos con igual frontalidad, de la que no está apartado un tono agresivo (393-5, 420-3). Héctor se adelanta para censurar el retraso del tracio, exponiendo, con esa demora, Troya al enemigo y asumiendo un comportamiento inferior en su compromiso al que muchos otros aliados habían adoptado. Se encamina entonces a un enunciado de principios sobre lo que son las exigencias de la philía, la "solidaridad", y 
de la cháris, la "gratitud" (399-412). La ayuda de Reso ha sido pedida en varias oportunidades, por lo que no podrá argumentar que desconocía la crisis vivida en Troya: las ofrendas que acompañaban a las embajadas fueron generosas; los deberes -de parentesco, amistad e incluso comunión de intereses como miembro de una comunidad de bárbaros-, innegables; sumados a favores recibidos en el pasado, cuando, gracias a la intervención troyana, la autoridad de Reso se impuso entre tracios revoltosos e insumisos. La cobranza retributiva que ahora se pide al acreedor de estos deberes y beneficios está, al final, cubierta de toda legitimidad.

En una simetría a la que los agônes comunes en la tragedia, sobre todo la de Eurípides, nos tienen acostumbrados, Reso desmonta los argumentos adversarios uno a uno. Comienza afirmando el desagrado que él mismo sintió con su retraso ( 424 y ss.), justificable tan solo con una lucha que tuvo que lidiar contra amenazas de pueblos vecinos, como esas que Héctor venía de recordar, dando credibilidad involuntaria al argumento. Fue entonces cuando, en una marcha forzada y cargada de peligros, se apresuró a responder al llamamiento de sus amigos troyanos. Y todavía más, no puede reprocharse que su llegada es inútil, porque se presentó en el momento oportuno de poner fin a una guerra que amenaza eternizarse "sin resultados" (445). Con su valoración "sin resultados", Reso está demoliendo, sin saberlo, la arrogancia antes afirmada por Héctor, que se consideraba el autor único y definitivo de una victoria contra el invasor. Partiendo de aquí, Reso avanza con afirmaciones que no carecen de hýbris ${ }^{31}$ - de que en un solo día podrá llevar a cabo, él solo, lo que diez años no han podido concretar-, logrando, con sus excesos de propósito y lenguaje, devolverle a Héctor, por contraste, algún sentido común.

Pues es ante las exageraciones del tracio que, por primera vez en la obra, el comportamiento de Héctor parece cambiar el rumbo de su trayectoria y dar lugar a una prudencia y equilibrio hasta ahora desconocidos. La propuesta del aliado de que, terminada la invasión con éxito para los troyanos, ambos procedan a un avance vengativo contra la Hélade despierta en el rey de Troya un sentimiento de responsabilidad y moderación (471-6, 480-4). Es como soberano de una ciudad poderosa que responde, más preocupado por la seguridad de su pueblo que en sumar a sus dominios, ya envidiables, más territorio. Vemos, por primera vez, a Héctor más preocupado por su pueblo que por sí mismo y respetuoso de una moderación de la que aún no se había mostrado capaz. Con esta decisión se abre camino a otro Héctor, más seguro y firme, aunque confrontado con acusaciones graves que tal vez apunten sobre todo a la imagen de precipitación y ambición que ha dejado en los que se relacionan o conviven con él.

La rehabilitación de la figura sucede en simultáneo con el desenlace de los acontecimientos. Es ante el auriga herido (738-44), que llega con la noticia de la muerte de Reso y de la matanza provocada por un asesino aún desconocido en el acuartelamiento tracio, que Héctor tiene su oportunidad de redención. Poco a poco sus cualidades de combatiente, que parecían ser las únicas que definían su personalidad, dan lugar a la dignidad y lealtad del amigo y aliado. El mensajero de la desgracia, que acaba de llegar, arrasa, sin apelación, las garantías y efectos de la victoria que el jefe troyano pensaba haber alcanzado el día anterior; porque al confiar en los troyanos, a punto de descuidar la guardia del acuartelamiento, los tracios fueron sorprendidos y exterminados por tan solo dos enemigos infiltrados (764-9). Pero no es solo de ineficacia que Héctor es acusado; la denuncia del auriga va aún más lejos cuando lo responsabiliza de traición, pareciendo inconcebible que cualquier enemigo circulase delante de las tropas troyanas, en el campamento, hasta llegar al ejército de los tracios, sin haber sido detectado. Así, en su deducción, lógica además, parece haber habido connivencia de Héctor en el crimen, o sea, la philía parece haber sido traicionada por intereses mezquinos e indignos $(803,855)$, los de apropiarse de los caballos envidiables que poseían los tracios (835-42). De cierta forma, las acusaciones antes dirigidas a Reso por negligencia en sus deberes de philía son ahora, por intermedio del auriga, retomadas y agravadas por la suposición de que el más elemental respeto a un aliado haya sido herido de traición.

Héctor crece, en el buen sentido, ante esta prueba límite. Él, que había empezado por manifestar su habitual irritación precipitada, atribuyendo a los propios centinelas que forman el coro una culpa de negligencia que 
repercute en vergüenza sobre su forma de comandar (808-19), se va humanizando ante el sufrimiento de un aliado. Su respuesta a las acusaciones del auriga es una defensa de la "solidaridad" en su sentido más puro, la que ninguna ambición mezquina puede socavar (856-60). Incluso antes de que una voz divina venga a clarificar quiénes son los responsables de los acontecimientos, Héctor olvida la injusticia de la acusación y se dispone a acoger en Troya a ese que representa lo que resta de un aliado perdido (870-2) y en cuanto a la víctima principal de la matanza, el comandante tracio Reso, le brinda homenajes dignos de un aliado y amigo (959-61).

\section{El Defensor De Troya y EL TRATAMiento DEL ENEMigo}

Más que reponer la opinión que los jefes aqueos puedan tener de Héctor -ya que los dos únicos representantes, en la obra, del campo enemigo son Odiseo y Diomedes, en misión de espionaje en territorio troyano-, ${ }^{32}$ la obra valoriza la actitud del jefe troyano ante el enemigo y las estrategias que prevé para aniquilarlo. Este es, como sabemos, un punto delicado en los códigos de comportamiento, épico y trágico, en el campo de batalla. Frontalidad y enfrentamiento directo, digno entre enemigos que se respetan y se miden por igual, es una credencial importante para el reconocimiento de un verdadero mérito y heroicidad. Hay que distinguir, es cierto, la existencia de excepciones, como es el caso de Odiseo, el forjador de embustes y manipulador de dolos, capaces de resolver dificultades y granjear victorias. Pero esa es una excepción que no confirma la regla y que justificó incluso, a lo largo de los tiempos, lecturas menos favorables del señor de Ítacaque tendió a identificarse con el demagogo falso y condenable dentro de criterios clásicos (papel ese que asume en Filoctetede Sófocles, o en Hécuba Ifigenia en Aulidde Eurípides, para mencionar tan solo algunos ejemplos).

La pretensión general que anima a Héctor en esta obra es, como vimos, consumar un avance ya logrado con la destrucción radical del enemigo. ${ }^{33}$ Por ello teme una fuga inesperada y oculta, que le frustre ese plan de victoria radical. Y no se trata de asegurar a Troya el fin de diez años de guerra y un regreso estable a la paz de otros tiempos, sino, sobre todo, de satisfacer ambiciones personales y sed de venganza. No dejan dudas las palabras con las que confiesa sus intentos (56-8): "Oh destino, me has robado, como a un león, mi banquete, ${ }^{34}$ antes de que pudiese con esta espada exterminar, sin apelación, al ejército argivo”. Con la colaboración de la noche, el destino bloqueó su deseo de eliminar al enemigo y hacer justicia al epíteto de

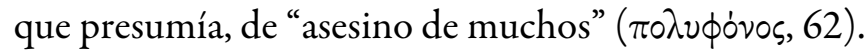

Para llevar a cabo ese objetivo, no vacila en recurrir a todos los procedimientos, valorando la traición y la trampa sobre un combate frontal y abierto. Estaría dispuesto a luchar en la oscuridad (63-4), sorprendiendo al enemigo desprevenido, sin incluso ponderar los riesgos extremos que ese ataque podría representar también para sus propios hombres. O bien, siendo tal cosa desaconsejada por los adivinos, estaría dispuesto a sorprender al enemigo en fuga y a abatirlo por la espalda, para matarlo o reducirlo a la esclavitud (72-5, 100-1).

Esta es la imagen que se va estableciendo de quien será, más allá de los límites de la obra, el adversario de Aquiles, el eje central de la resistencia adversaria (119-21), empeñándose en la defensa de sus compañeros. A diferencia de Héctor, una figura profundamente retocada en el Reso, el perfil que se diseña del Pelida, a distancia, por referencias que le hacen solamente sus enemigos, se mantiene fiel, en sus rasgos generales, al modelo de la Ilíada.

En última instancia, el resultado del tratamiento de los dos héroes termina aproximándose, sobre todo en lo relacionado con la ambición y la arrogancia. Así, desde luego en el diálogo que Eneas entabla con Héctor, el retrato del más temible de los enemigos es trazado en estos términos (122): "un individuo de ánimo ardiente, que se yergue como una torre de insolencia". ${ }^{35}$ Los caballos que usa, divinos de origen y dádiva de dioses a Peleo, forman parte de su imagen de areté y constituyen el mayor trofeo que cualquier enemigo estaría orgulloso de capturar. Son entonces para Dolón (182-3, 237-41) -e incluso para el propio 
Héctor (184) - un blanco a conquistar, como prueba de la victoria definitiva, alcanzada sobre el enemigo con la sumisión del rey de Ftía. Aquiles está, por lo tanto, siempre presente en el espíritu del enemigo como un adversario difícil de vencer. Hay, sin embargo, una diferencia esencial que parece siempre implícita en estas escasas menciones: Aquiles no pertenece al número de los que huyen o se dejan herir por la espalda; por ello, la estrategia de engaño que Héctor imagina victoriosa contra el enemigo no funcionará delante del más temible de los aqueos. Y ¿será que el Héctor personaje del Reso, independientemente de la voluntad divina, con su precipitación y falta de ponderación, tendría condiciones para cambiar el resultado que la tradición consagró, el de la victoria del Pelida?

\section{Conclusión}

Parece claro que Héctor cumple el papel de un verdadero protagonista en el Reso. Le toca centrar la intriga y, en sucesivos diálogos, contribuir en el diseño de un verdadero jefe heroico, no porque lo sea, sino exactamente porque los errores que comete y las censuras que provoca son el punto de partida para la discusión de principios fundamentales en un verdadero código de honor, philía, symmachia, xenía, timé, areté.

En comparación con su modelo homérico pierde en calidad, más centrado en un egoísmo algo narcisista y menos atento a la salvaguarda de los intereses de la comunidad y de los ciudadanos y familiares que dirige. Por ello, pierde en la consideración de sus subordinados, que tienden a compararlo, siempre en desventaja, con paradigmas más prometedores, como Reso o el propio Aquiles.

Hay, sin embargo, que reconocer en este Héctor trágico un diseño y una evolución psicológica y humana que le enriquece el perfil. No hay rigidez en su actitud, pese a la coherencia innegable que lo asiste. Afrontar el sufrimiento, que no controla, a pesar de la convicción de las victorias alcanzadas, despierta en él alguna humanidad generosa y lo hace defensor de un aliado, en el justo momento en el que, por un golpe del destino, la colaboración que de él podría esperar fracasa. Será este, en la obra, el resultado de un ajuste que se va haciendo más evidente entre los proyectos humanos y una mano superior que todo lo condiciona.

\section{EDICIONES Y COMENTARIOS}

Kovacs, D. (2002) Euripides: Bacchae, Iphigenia at Aulis, Rhesus, Cambridge-Massachusetts-London. Liapis, V. (2012) A Commentary on the Rhesus attributed to Euripides, Oxford.

\section{Bibliografía CitAdA}

Albini, U. (1993) “Teatralità del Reso", PP 269: 81-87.

Battezzato, L. (2000) "The Thracian camp and the fourth actor at Rhesus 565-691", CQ 50. 2: 367-373.

Björck, G. (1957) “The authenticity of Rhesus”, Eranos 55. 1-2: 7-17.

Bond, R. S. (1996) “Homeric echoes in Rhesus”, AJPh 117. 2: 255-273.

Burkert, W. (1985) Greek Religion, Oxford.

Burkert, W. (1987) Ancient Mystery Cults, Cambridge-Massachusetts-London.

Fantuzzi, M. (2007) “La mousa del lamento in Euripide, e il lamento della Musa nel Reso ascritto a Euripide”, Eikasmos 18: 173-199.

Fantuzzi, M. (2016) "Dolon euergetes: Ps.-Euripides, Rhesus 149-190 and the rhetoric of civic euergesia", CQ 66. 2: 514-524.

Kitto, H. D. (1977) “The Rhesus and related matters", YClS 25: 317-350.

Pace, G. (2000) “Eur. Rh. 454-466; 820-832”, QUCC 65. 2: 127-139. 
Pagani, G. (1970) "Il Reso di Euripide: il dramma di un eroe”, Dioniso 44. 1-2: 30-43.

Poe, J. P. (2004) "Unconventional procedures in Rhesus", Philologus 148. 1:21-33.

Ritchie, W. (1964) The authencity of the Rhesus of Euripides, Cambridge.

Roisman, H. (2015) "Rhesus' allusions to the Homeric Hector", Hermes 143. 1: 1-23.

Rosivach, V. J. (1978) "Hector in the Rhesus", Hermes 196. 1: 54-73.

Taplin, O. (1977) The stagecraft of Aeschylus. The dramatic use of exits and entrances in Greek tragedy, Oxford.

\section{Notas}

* Es Profesora Catedrática del Instituto de Estudios Clásicos de la Facultad de Letras de la Universidad de Coímbra. Como helenista, enseña lengua y literatura griega antigua, en particular temas de teatro griego, en cursos de grado y posgrado. Su investigación se ha centrado especialmente en teatro e historiografía y, más recientemente, en los estudios de recepción. Tradujo al portugués textos de varios autores, entre los que se destacan Aristófanes, Herodoto, Aristóteles, Teofrasto, Caritón. Publicó diversos libros y artículos, como Crítica do teatro na Comédia Antiga (1987), Ensaios sobre Euripides (2005), Ensaios sobre Aristófanes (2007), Ésquilo, o primeiro dramaturgo europeu (2005), Portrayals of Antigone in Portugal. 20th and 21st Century rewritings of the Antigone myth (2017), Portraits of Medea in Portugal during the 20th and 21st Centuries (2018).

1 La Hipótesis II, adjunta al texto que nos ha llegado, comprueba la antigüedad de esta discusión.

2 En el estudio introductorio que acompaña su edición del Reso, Liapis (2012) identifica muchas innovaciones que atribuye a la incompetencia del autor ante las convenciones del género. La identificación de estas incongruencias conduce a la posición de fondo de este editor: que el Reso que nos llegó no es de Eurípides.

3 En Kitto (1977: 317-350), Battezzato (2000: 367) y Roisman (2015: 2) podemos encontrar un resumen de los adeptos a esta hipótesis, así como de los que se mantienen fieles a la autoría de Eurípides. Para los estudiosos que defienden esta autoría, en línea con Ritchie (1964), autor de argumentos pormenorizados en favor de esa tesis (cf. Björck, 1957: 7-17), el Reso sería una obra de la primera etapa de la carrera del poeta -consideradas las imperfecciones o la inmadurez-, con una fecha próxima al 440 a. C.

4 La Hipótesis III de Aristófanes de Bizancio es, en este sentido, un testimonio relevante.

5 Rosivach (1978) defiende justamente la idea de que la cohesión de la intriga, que muchos comentadores cuestionan, depende de la intervención dada a Héctor. Por su parte Roisman (2015: 2) no duda en afirmar que, pese al título de la obra, "Héctor es el personaje central del drama".

Las traducciones del griego responden a la edición de Kovacs (2002).

6 Albini (1993: 82-83) registra cómo el diseño que el autor del Reso hace de los tres personajes centrales -Héctor, Dolón y Reso- no los vuelve simpáticos, antes "les destaca la perversa euforia y arrogancia".

7 La escena de apertura de la tragedia puede tener como fuente el fragmento de la Ilíada II. 802-806, en el que Héctor es abordado por Iris, mensajera de los dioses, bajo la apariencia de su hermano Polites, de guardia en las murallas de Troya, con motivo de animar a la movilización de sus hombres. Roisman (2015: 4) insiste en una cierta inconsciencia o debilidad del jefe que es Héctor, dormido en una hora crucial, y valora este efecto por contraste con la importancia, visible en Iliada X, de que los jefes se mantengan despiertos (X.1-4, 25-8, 67, 97-9, 109-16, 124, 138-47, 150-67, 175-9, 181-93, 299-302, 385-6), como señal de liderazgo y responsabilidad.

8 Las luces en el campamento argivo sirven a la organización de una asamblea frente a la tienda de Agamenón (cf. Ilíada IX.9-78).

9 La secuencia de imperativos que el coro usa en este pasaje, así como las sucesivas preguntas que parecen cuestionar alguna inercia dentro del ejército, invierten la jerarquía entre jefe y subordinados.

10 La posibilidad de que se trate de una maniobra de fuga es sugerida por Ilíada X.147, 327 y por la naturalidad con la que el encendido de antorchas se considera una estrategia para encubrir la fuga, convenciendo al enemigo de que el acuartelamiento se mantiene con normalidad.

11 Son de censura las palabras con las que el coro, sin dejar de reconocer el éxito alcanzado, destaca su imprudencia (83):

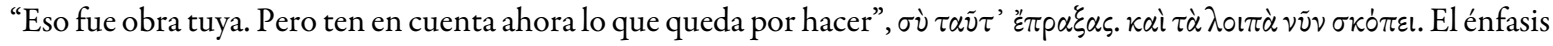
puesto en el pronombre personal y el contraste entre los tiempos, marcados por un aoristo de acción consumada, seguido de $\tau \dot{\alpha} \lambda \circ \imath \pi \dot{\alpha} \nu \tilde{v} \nu$, en una perspectiva que apunta a un futuro que debe ponderarse ahora, manifiestan cuán reducida es la convicción del jefe troyano.

12 El temor a la "vergüenza” es, en la jerarquía de razones que Héctor establece, lo que considera prioritario. Por ello, lo coloca a la cabeza de sus preocupaciones y lo repite de forma obsesiva (102): "Pues será una vergüenza, y además de

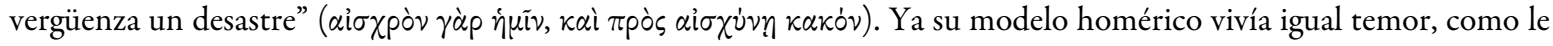


confiesa a Andrómaca, que intenta retenerlo apartado del combate (VI.441-3), contraponiéndole razones de un código militar que le exige exponerse en nombre de la gloria (VI.444-6).

13 Idea equivalente de que capacidad bélica y consejo son méritos distintos, y de que Héctor es hábil en la primera, pero no en el segundo, está expresada en Ilíada XIII.726-34.

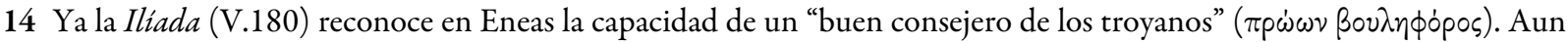
así, él puede ser también, en la épica, el buen guerrero susceptible de alguna imprudencia, justamente el modelo que aquí censura (cf. Ilíada XX.200-92).

15 Es relevante notar que la decisión de enviar un espía es tomada, en Ilíada X.308-12, por Héctor de una forma autónoma, lo que deja en evidencia la pérdida de lucidez y autonomía del jefe troyano en la tragedia.

16 Es verdad que el Héctor épico no está inmune a las censuras de sus compañeros, a pesar de sus reconocidas cualidades. Así, por ejemplo, Sarpedón (Il. V.471-7), un aliado de Troya, le reprocha la falta de vigor y alguna fisura en su lucidez para el mando (IV.485-8); más tarde también (VI.80-7), su hermano Heleno les dirige a él y a Eneas palabras de ánimo, temiendo que una señal de cobardía lo exponga a la risa de sus enemigos, y le aconseja sobre qué iniciativas tomar.

17 Ilíada X.314 identifica al padre de Dolón como Eumedes, un hombre rico cuyo mérito resultaba de su función de heraldo; la gloria por logros militares no le estaba propiamente asociada en la épica. Sobre la riqueza de que Dolón era dueño, véase Reso 178.

18 En la Ilíada, donde su encuentro y muerte a manos de los espías adversarios son minuciosamente relatados, Dolón representa con propiedad al cobarde. En la tragedia, el voluntario troyano no expone de forma tan degradante esa característica, aunque se entienda que pasó informaciones al enemigo que colocan en riesgo de vida a su jefe. Además de esa nota, el interés por el personaje desaparece, después de que su oferta para asumir su misión y la decisión de la recompensa se fijen a la vista del público. La muerte que lo penaliza no merece siquiera el relato de un mensajero, sino tan solo una información indirecta y lacónica dada por sus dos asesinos, Odiseo y Diomedes, con la indiferencia que merece una simple anécdota de paso.

19 Cf. el llamamiento equivalente de Héctor en Ilíada X.303-304, al que se sigue un silencio general finalmente interrumpido por Dolón (X.313). Manifiestamente en el Reso la pregunta sobre voluntarios se multiplica, lo que representa de otro modo el silencio y la hesitación general ante la peligrosidad de la misión. Tanto más expresivo resulta el avance de Dolón. Liapis (2012: 105) enumera el elevado número de pasajes (154-5, 158-80, 291-3) que ponen de manifiesto un propósito de rehabilitación de Dolón en contra de su perfil en Homero; aunque, en nuestra opinión, esa determinación no esté exenta de marcas de ambición eventualmente más acentuadas que las sugeridas por la versión épica. En la Ilíada es su cobardía lo que predomina: al darse cuenta de la presencia de los enemigos, huye (X.354-9); no logra esconder las evidentes señales de miedo (X.374-81, 390); y se humilla delante de los perseguidores (X.442-5). En la tragedia, algunas señales de igual miedo, y de la traición que supone, subsisten: es Dolón quien revela a sus asesinos la clave que permitirá a Odiseo escapar después de llevada a cabo la matanza de los tracios, así como la ubicación de la tienda de Héctor, que los dos infiltrados intentaban eliminar. Sin embargo, aun así es visible que la cobardía se diluye en favor de la ambición.

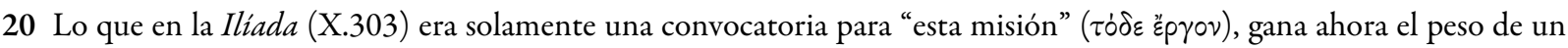
rasgo de patriotismo y de una elevada búsqueda de gloria (cf. verso 158, en el que Héctor aplica a Dolón el epíteto de

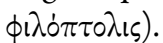

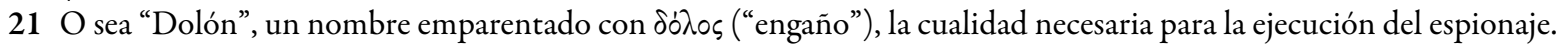

22 Ya era de todos bien conocido (cf. Ilíada X.322-3) que el premio pretendido por Dolón no existía en Troya.

23 Un pormenor es importante destacar en relación con el premio de los caballos de Aquiles. En la Ilíada, donde Héctor toma la iniciativa de anticipar un premio al voluntario para la misión, lo que promete no va más allá de una pareja de caballos de excelencia (X.304-6); la idea de que se trate específicamente de los caballos del Pelida es adelantada por Dolón un poco después (X.392-3), ya ante los espías enemigos.

24 El deseo de Héctor de ser dueño de esos caballos no está en la Ilíada, es una novedad en la pieza.

25 Cf. Iliada X.305.

26 Roisman (2015: 18) destaca como significativa la desproporción entre el Mensajero, un campesino sin preparación militar, pero perspicaz en la valoración de las circunstancias, y Héctor, el jefe militar al frente de la defensa de Troya, que parece lento en comprender las razones de prudencia del aliado que acaba de llegar.

27 En Iliada X.439-41 se hace la misma aproximación entre la imagen asombrosa de Reso y un dios.

28 Nadie más parece convencido, en la obra, de esta excelencia de Héctor y de su capacidad de doblegar, él solo, al adversario. Por ello el coro aplaude la llegada de Reso como la de un libertador (355-6, 367-9) y se anima con sus méritos (380-7).

29 Héctor se propone cumplir una mera etiqueta social, la regla de la hospitalidad, sin ninguna otra vinculación más comprometedora.

30 El Héctor homérico también tiene que enfrentarse a algunas divergencias con sus aliados, pero manifiesta siempre su preocupación de superar, con concesiones, esas dificultades (V.472-92, XVI.538-43, XVII.140-68), consciente de la importancia que todos ellos tienen para reforzar su ejército, desproporcionalmente pequeño en comparación con el de 
los invasores. Por su parte, la entrada de Reso, en la Ilíada (X.300-39) solo uno más de los aliados troyanos que acaba de llegar, a quien no se le da voz en ningún momento, conduce en la tragedia a un tratamiento distendido e innovador. De una presencia apagada, traducida en pocos versos en la Ilíada, el rey tracio pasa ahora a ser profundizado en el diseño de su carácter y enriquecido con valores éticos.

31 Cf. los comentarios aprensivos del coro en 453-6, ante lo que considera también un orgullo manifiesto y excesivo de Reso.

32 Por lo demás, la intención que ambos traían de matar a Héctor (575-6), seguramente aprovechando alguna desmovilización que imaginaban haber seguido a la convicción de la victoria (579) -en lo que tenían razón, como el sueño del jefe troyano confirmaba-, no era conforme con la determinación de los dioses y, por ello, se ve aplazada hacia fuera del ámbito de la obra (595-8, 605-7). El autor del Reso se mantenía, pues, fiel a la tradición de que Héctor habría de caer en manos del primero de los jefes aqueos, Aquiles.

33 Esta rhêsis del jefe troyano (52-75) presenta similitudes con un discurso equivalente, dirigido por el Héctor homérico a sus subordinados en Ilíada VIII.497-541, en idénticas circunstancias, cuando la llegada de la noche impide la consumación de una victoria que el avance alcanzado durante el día hacía prometedora. El temor por la fuga del enemigo, que deje inconcluso el éxito troyano, también se corresponde.

34 El lamento de Héctor por no haber podido arrasar a los aqueos está inspirado en Ilíada VIII.497-501. La terminología relacionada con $\varepsilon \dot{\tau} \tau \chi \varepsilon \tilde{\iota} \nu$ se repite en la obra, convirtiendo la buena expectativa que los troyanos tienen de la ventaja que llevan sobre el enemigo en un tema destacado; cf. 60, 64, 319, 390, 583, 649, 882.

35 Más abajo, cuando, con la llegada de Reso, la amenaza contra los aqueos parece encarnar en un nuevo protagonista, sigue siendo Aquiles, como el mejor de los enemigos, quien asoma al espíritu del Mensajero, impresionado con la superioridad del tracio (315-6; cf. igual opinión del coro, 370-1, 461-2, del propio Reso, 491, e incluso de Atenea, 601); ¿será que ni el hijo de Peleo podrá resistir tal embestida? 